\title{
Los archivos de Melilla la Vieja y su dispersión documental
}

FRANCISCO MIR BERLANGA

Cronista Oficial de Melilla

Prescindiendo de otros antecedentes más remotos, la Melilla española, es decir, la Melilla conquistada por don Pedro de Estopiñán, el 17 de septiembre de 149 ? (1), trae su origen, en la fortaleza o presidio que se estableció tras su conquista, tomando la palabra presidio en la acepción noble, con que la define el Diccionario de la Real Academia de la Lengua Española, "Guarnición de soldados que se pone en las plazas, castillos y fortalezas, para su guarda y custodia". Este origen castrense ha enriquecido en el pasado la historia de Melilla y su posterior vida urbana.

El caso de Melilla no ha sido único. Baste recordar, que entre otras, las ciudades de León, Cáceres y La Línea en España, Villa Sanjurjo -hoy Alhoceima - en Marruecos, Estrasburgo en Francia, Turín en Italia, Colonia en Alemania, y otras innumerables ciudades de Europa, Asia y América, deben su origen a una guarnición militar, a cuyo abrigo, se fue instalando la población civil.

Así también ocurrió en el caso de Melilla, donde la tenacidad de los españoles triunfó sobre el medio hostil: hasta conseguir transformar la pequeña ciudadela, en la hermosa ciudad actual. 
La situación geográfica de Melilla, separada de la Península por el mar, y aislada por tierra, en el pasado, por la hostilidad de las cabilas fronterizas, planteó, desde el momento de su conquista, el problema de las comunicaciones con la metrópoli.

Ya en el primer Asiento que "para la guarda e probeimiento de la ciudad de Melilla", fue firmado en Alcalá de Henares el 13 de abril de 1498 entre la Corona y los representantes del duque de Medina Sidonia, se dispone que la plaza debe tener "cuatro fustas de remos bien pertrechadas $y$ aparejadas y cuarenta hombres para su servicio", encargados de mantener las comunicaciones con España.

Al duque de Medina Sidonia le correspondía la tenencia de la plaza, y por lo tanto era el responsable de su seguridad. Los primeros alcaldes fueron nombrados por el duque, y con él se entendían, para todo lo relacionado con el gobierno, conservación y defensa de Melilla.

Pero Sanlúcar de Barrameda, —residencia de los duques- de donde partió la expedición conquistadora. quedaba lejos. Por lo que pronto sería Málaga, la ciudad, desde donde se atenderían las necesidades de Melilla. Un factor o apoderado del duque, destacado en Málaga, se encargaría de aquella misión.

Desde Málaga llegaban el correo, los hombres y las provisiones de boca y guerra. Pero a partir de 1556 en que los Medina Sidonia renunciaron a Melilla, será la Corona, la que se encargará directamente, de atender a la conservación y defensa de la fortaleza (2) que es abastecida por los proveedores reales, residentes en Málaga.

En el periodo comprendido entre la ocupación en 1497 y el citado año de 1556 en que renuncian los duques, el archivo de la Casa Ducal, hoy en trance de rigurosa ordenación, es la fuente indiscutiblemente preferente para el estudio de la historia de Melilla.

Juan Antonio Estrada y Paredes (3), autor de la Población General de España, sus Reinos y Provincias, Villas, Pueblos, Islas Adyacentes y Presidios de África, de la que conocemos dos ediciones, hechas en los años 1746 y 1768, proporciona numerosos datos sobre la historia de la ciudad de Melilla, de donde era natural y dice; "Esto que hemos referido consta en 
los Archivos y Papeles del Duque de Medina Sidonia, que nos mostraron para este efecto, y de otras noticias que he buscado con bastante trabajo. porque hay poco escrito de Presidios, y lo que de ellos se refiere es muy sucinto y con alguna confusión...".

Como queda dicho, a partir de 1556 la ciudad pasó a depender de la Corona. Melilla, por su situación estratégica, tendría un importante protagonismo militar, en una doble misión. Como centinela avanzado de la seguridad nacional ante un Magreb inestable, desgarrado por las luchas de las diversas dinastías que sucesivamente se disputan el poder, y frente a la acción constante de la temida piratería turca y berberisca, azote grave de las costas españolas...

Desde la Corte se envían a Melilla las órdenes e instrucciones pertinentes. Unas y otras se notifican y asientan por duplicado. Primero por los alcaldes-gobernadores, máxima autoridad de la plaza. Luego pasan a los veedores, encargados, entre otras funciones, de vigilar el cumplimiento de las Órdenes Reales, que quedan archivadas. Así con el transcurso de los años, van formándose los archivos melillenses.

A veces, las órdenes tienen que ser reiteradas, porque hay correos que no llegan a su destino, por la pérdida de la embarcación que las conducen, unas veces como consecuencia de los temporales, y más frecuentemente por la acción de los piratas, que amparados en el cabo de Tres Forcas, asaltaban las embarcaciones destinadas a mantener la vital comunicación entre Málaga y Melilla. Existe constancia documental, de numerosos ataques y capturas de los piratas.

En alguna ocasión, los enemigos alcanzaron notables éxitos, como el del día 2 de septiembre de 1549, en el que un corsario argelino se apoderó de la carabela de Melilla, donde viajaba el propio alcalde Francisco de Medina que quedó cautivo (4).

Por su parte, los alcaldes, dirigían sus escritos y peticiones directamente a los Reyes. Pero cuando se trataba de algún caso urgente, que no admitía demora, las peticiones se hacían a las autoridades de Málaga, que procuraron remediar la situación de Melilla, según consta en los Libros Capitulares del municipio malagueño (5), que la cortesía de don Francisco Bejarano, me permitió conocer. 
De lo hasta ahora expuesto, han quedado señaladas las tres fuentes documentales más importantes de Melilla en los archivos peninsulares, que son el de los Medina Sidonia. los de la Monarquía y los de la ciudad de Málaga.

Hablaremos ahora de los de la propia ciudad de Melilla.

Desde la Atalaya de la Torre de la Concepción Alta, se vigilaban cuidadosamente los movimientos de las escuadras turcas y berberiscas, que utilizaban la mar Chica como refugio. Cuando los avisos llegaban a tiempo, se pudieron evitar graves daños. Muchos de los pacíficos habitantes, de los bellos pueblos costeros andaluces, debieron su libertad o su vida, tal vez sin sospecharlo, a los diligentes avisos de los alcaldes de Melilla.

Concentraban éstos, en sus manos, toda clase de poderes civiles y militares, incluso los judiciales. De ahí el refrán de "ser rey en Castilla o alcalde en Berbería"... para significar la plenitud de poderes, como veremos a continuación.

En el mes de octubre de 1555 se descubrió una conspiración, con el propósito de dar muerte al alcalde don Alonso de Gurrea y entregar la plaza al enemigo. Los conspiradores fueron condenados a muerte y ejecutados.

Pero dejemos el relato al propio don Alonso, que en carta dirigida a los Príncipes Regentes con fecha 10 de noviembre de 1555 les decía: "Condené a muerte al Contador y a otros cuatro soldados con él, en los que hice Justicia. Al Contador y a otros tres, ahorqué y les corté la cabeza y las enclavé en la muralla, y al otro condené perpetuamente a galeras, por ser muchacho y no le hallar tan culpable..." (Simancas. Guerra Antigua. Legajo 60).

Respecto a un clérigo, que también tomó parte en la conspiración, y que según Gurrea era "El más mal hombre que hay en el Mundo", no se atrevió a ejecutarlo, por su condición sacerdotal, remitiendo el proceso a la superioridad, para que resolviera.

Según Gabriel de Morales (6) el clérigo fue también condenado a muerte y ejecutado.

Con estos castigos ejemplares, terminó la conspiración, que en tan grave riesgo puso la seguridad de Melilla.

Toda la vida de la ciudad quedó reflejada en el Archivo del Gobierno de la plaza, salvo la iglesia que tenía su propio Archivo. Los valiosos documentos, que del pasado han podido conservarse, así lo atestiguan. 
Las importantes circunstancias bélicas por las que pasó Melilla acentuaron el carácter militar de su gobierno y administración. Este régimen castrense, estuvo en vigor hasta bien entrado el presente siglo. Pero el rápido aumento de la población. y la natural evolución de la ciudad, que había dejado de ser plaza fuerte, impusieron la separación y especialización de funciones, y la implantación progresiva de una administración civil.

Esto dio lugar a una irreparable dispersión documental del Archivo melillense, aunque algo se salvó y quedó en Melilla.

La Junta Municipal creada en 1845, origen remoto del actual Ayuntamiento, recibió una pequeña parte de documentos civiles.

El antiguo Gobierno Militar de la plaza, convertido en Capitanía General y más tarde en Comandancia General, se llevó la parte más importante del Archivo, que hasta el año 1895, en que Gabriel de Morales (7) llegó por primera vez a Melilla, se encontraba intacto, y pudo utilizarlo para la redacción de sus importantes trabajos históricos.

Los Protocolos de los antiguos Escribanos de Guerra, quedaron en la Notaría Civil, desde donde pasaron el Archivo Histórico de Melilla, creado en octubre de 1969 (8).

Un precioso libro, bastante maltratado por los años, en el que se contiene un "Estado General de Casas, Cuevas y Solares, que el Rey y distintos particulares, tiene en esta Plaza", pasó al moderno Registro de la Propiedad.

Lo formó en 1753 don José de Osorio, que ostentaba el pomposo cargo de "Comisario de Guerra de los Exercitos de su majestad Veedor, Contador, Ministro de Hacienda, Marina, y Almirantazgo en esta Plaza...".

En este libro, por calles y plazas, está descrita la propiedad pública y privada existente en la pequeña Melilla de mediados del siglo XVIII.

Por si la anterior dispersión del Archivo de Melilla la Vieja no fuera suficiente, en 1927, al término de las Campañas de Marruecos, que habían durado 18 años, el entonces Ministerio de la Guerra, creó una Comisión de Jefes de Estado Mayor, encargados de redactar, la que habría de ser Historia de las Campañas de Marruecos, en la que Melilla y los territorios de su Comandancia General, habían tenido un importante protagonismo. 
La Comisión, a fin de documentar adecuadamente la obra proyectada, recabó para ella una serie de importantes documentos, que ya no volvieron a sus Archivos de procedencia, pero que afortunadamente quedaron en el Servicio Histórico Militar.

Esta es la breve historia con las limitaciones impuestas por el tiempo, de la dispersión de los Archivos de la Vieja Melilla.

Como se deduce de lo expuesto, la documentación de carácter histórico que de Melilla se conserva en la ciudad, es escasa y poco importante. En cambio es muy valiosa la conservada en el Archivo del Ayuntamiento, aunque referida exclusivamente al presente siglo.

Tampoco quedaron en Melilla los antiguos libros parroquiales que fueron remitidos al Obispado de Málaga. Son extraordinariamente interesantes, porque a parte de las naturales inscripciones de nacimientos, matrimonios y defunciones, el celo de los sucesivos vicarios les llevó a consignar en ellos importantes sucesos locales.

Hoy, el conjunto documental histórico de Melilla, se encuentra repartido en los Archivos de los duques de Medina Sidonia, en Simancas, Archivo Histórico Nacional, Sección de Manuscritos de la Biblioteca Nacional, Servicio Histórico Militar, Archivo Municipal de Málaga, el Histórico Provincial de la misma ciudad, así como el del Obispado.

Todos son de indispensable consulta para el estudio y conocimiento de la Historia de la ciudad de Melilla, que en 1997 cumplirá el medio milenio de su incorporación a la Corona de España, incorporación que tuvo lugar, 18 años antes de que lo hiciera el Reino de Navarra y 279 años antes, de que existieran los Estados Unidos de América... 
1. Los Reyes Católicos recibieron con gran satisfacción la noticia de la ocupación de Melilla, y escribieron al duque, con fecha 18 de octubre diciéndole: "Os certificanos que el servicio que nos hiziste con la toma de Melilla nos ha aprovechado para templar en algo el dolor que tenemos, porque esperaos en Dios. que desto será mucho servido". El dolor a que se refieren los Reyes era la reciente muerte del Príncipe Don Juan, fallecido en Salamanca el día 4 de octubre de 1497.

2. El duque de Medina Sidonia renunció a la Tenencia de Melilla, como consecuencia de los cuantiosos gastos que le ocasionaba.

3. Juan Antonio Estrada y Paredes, nació en Melilla, siendo bautizado el día 24 de enero de 1695 en la iglesia parroquial de la Purisima Concepción. Fueron sus padres el alférez de Infantería don Luis de Estrada y doña Andrea de Paredes..
4. El Alcalde Francisco de Medina, fue rescatado más tarde por la generosidad del conde de Alcaudete, gobernador de Orán.

5. Francisco Mir Berlanga, "La derrota de don Carlos Ramírez de Arellano y el socorro de Málaga a Melilla", en Melilla en los pasados siglos, Madrid, 1980.

6. Gabriel de Morales, Datos para la historia de Melilla, Melilln, 1909.

7. Francisco Mir Berlanga, "Gabriel de Morales ilustre historiador de Melilla", Revisıa Trápana, números 3 y 4, 1989-1990.

8. El Archivo Histórico de Melilla fue creado por el Ministerio de Cultura a petición del Ayuntamiento de Melilla, que presidía como alcalde, Francisco Mir Berlanga. 